\title{
ADMINISTRAÇÃO PÚBLICA, DIREITO E REDES SOCIAIS: O CASO DA CGU NO FACEBOOK
}

\author{
PUBLIC ADMINISTRATION, LAW AND SOCIAL NETWORKING: \\ THE CGU CASE ON FACEBOOK
}

\begin{abstract}
ANA Cláudia FaRRANHA
Possui graduação em Direito pela Universidade Federal do Espírito Santo (1991), mestrado em Ciência Política pela Universidade Estadual de Campinas (1999) e doutorado em Ciências Sociais pela Universidade Estadual de Campinas (2006). É professora adjunta da Faculdade de Direito - Universidade de Brasilia - FD/UnB, desenvolvendo atividades na área de Direito e Gestão Pública. Professora Programa de Pós Graduação Direitto ( PPGD/Un) e do Programa de Pós Graduação em Transporte da UnB - PPGT/UnB. Coordenou a pesquisa Administração Pública e Redes Sociais, financiada com recursos do CNPq. Tem experiência na área de Ciência Política e Direito, atuando principalmente nos seguintes temas: Estado, marco regulatório e políticas públicas; pobreza, poder político, poder e desenvolvimento local; gênero e raça e direitos humanos e temas relacionados com a promoção da equidade e avaliação de políticas públicas. É líder do Grupo de Pesquisa GEOPP (Grupo de Estudos Obervatório de Políticas Públicas), da Faculdade de Direito da UnB ( FD/UnB) anclaud@uol.com.br
\end{abstract}

LEONARDO TADEU DOS SANTOS Graduando em Gestão Pública, pela UFMG. Aluno da UnB (Universidade de Brasilia) em mobilidade estudantil. Membro do Grupo de Pesquisa GEOPP (Grupo de Estudos Obervatório de Políticas Públicas), da Faculdade de Direito da UnB ( FD/UnB) leonardotadeu17@gmail.com

\section{RESUMO}

O presente artigo é resultado da pesquisa sobre direito, administração pública e redes sociais. Tem-se por objetivo discutir como o uso das redes sociais, por órgãos públicos podem auxiliar na execução de dispositivos legais normatizados por lei e como a atuação da administração pública nas redes sociais pode, ou não, fomentar uma cultura de informação e politização, estudando o caso da CGU. A metodologia usada é o estudo de caso e reside basicamente no monitoramento das páginas virtuais, revisão da literatura e de entrevistas. 0 estudo insere-se no campo dos estudos relacionados ao governo eletrônico, pois, busca-se, por meio dele, identificar se o princípio da publicidade pode ser melhor efetivado através de mídias sociais. Conclui que, apesar de grandes avanços no governo eletrônico, a atuação de órgãos públicos auxiliam na implementação do Direito à Informação, porém essa perspectiva se dá de forma descontinua, cujos obstáculos para o fortalecimento de uma cultura de informação e politização efetiva nos usuários parece ser um dos desafios que atravessa o tema.

Palavras-chave: Direito ao Acesso à Informação, Administração Pública; Governo Eletrônico;Redes Sociais.

\begin{abstract}
This article is the result of research on law, public administration and social networks. It has as objective to discuss how the use of social networks for government agencies can assist in the execution of legal devices regulated by law and how the performance of public administration in social networks may (or not) promote a democratic experience. For this article we are studying the case of CGU. The methodology used is the case study and in the monitoring of virtual pages, review of the literature and interviews. The study is part of the field of studies related to e-government therefore seeks to, through him, to identify whether the principle of advertising can be best effected through social media. It is concluded that although great strides in egovernment, the role of public agencies assist in implementing the Right to Information, but this perspective takes place in discontinuous form, whose obstacles to the strengthening of a culture of information and affective politicization in users seems to be the biggest challenge that crosses the topic.
\end{abstract}

Keywords: Right to Information, Public Administration, Electronic Government, Social Networks. 


\section{SUMÁRIO}

INTRODUÇAO; 1 APRESENTANDO CONCEITOS; 2 MONITORAMENTO DA PÁGINA OFICIAL DO FACEBOOK DA CGU; 2.1 Panorama geral das postagens; 3 INTERAÇÃO VIRTUAL; 4 A VISÃO DO ÓRGÃO: ENTREVISTAS REALIZADAS; 4.1 Entrevista com a assessoria de comunicação; 4.2 Entrevista com a Equipe Técnica; 4.3 Considerações sobre as entrevistas; 5 POSTAGENS SOBRE A LEI DE ACESSO A INFORMAÇÃO; CONCLUSÃO; REFERÊNCIAS.

\section{INTRODUÇÃO}

É possível pensar que as Redes Sociais Digitais, tais como Facebook ou outras mídias podem produzir a construção de uma sociedade mais democrática e pautada em uma cultura da informação? A questão pode até ter como resposta um não, fundamentado no fato de que a democracia merece um espaço mais privilegiado e não pode ser confundida com xingamentos e ódios de toda sorte, tais como os que se encontram nas redes sociais. Entretanto, o que dizer dos muitos perfis de órgãos públicos que estão em ação em redes como Facebook, Twitter, Google +, Youtube? O que a Administração Pública Federal faz nestas redes?

Essas eram as perguntas iniciais que levaram a construção do Projeto de pesquisa Administração Pública e Redes Sociais, financiada com recursos do Conselho Nacional de Desenvolvimento Científico e Tecnológico - CNPq. Tratou-se de uma investigação sobre perfis da Administração Pública nas redes sociais Facebook e Twitter , buscando identificar qual o sentido da presença destes órgãos nestes espaços virtuais.

Para esse texto especificamente, investiga-se o perfil do Facebook mantido pela Corregedoria Geral da União - CGU, com objetivo de analisar se é possível identificar nesse espaço os elementos de uma cultura da informação, da ampliação do ativismo e participação e de práticas relacionadas a promoção da transparência passiva e ativa, conforme, definido pela Lei de Acesso à Informação (lei ${ }^{\circ}$ 12.527/2001)

A metodologia do artigo se baseia em estudo de caso, com coleta de dados do perfil oficial da instituição na rede social Facebook, entrevistas com funcionários do órgão e revisão da literatura, que permite a construção de um arcabouço teórico que auxilia na compreenção de conceitos básicos são desenvolvidos ao longo da abordagem. Ressalta-se que as técnicas e 
métodos que ora são apresentados podem ser replicados em outros estudos de caso sob a mesma perspectica, fortalecendo a perspectiva da pesquisa empírica no Direito.

A escolha da página do Facebook da Controladoria Geral da União se deu devido a sua característica voltada para a defesa do patrimônio público e a promoção da transparência da gestão. Sendo assim, trata-se de um órgão fortemente comprometido com o uso do governo eletrônico, bem como com suas implicâncias e obstáculos.

0 artigo está estruturado em quatro partes: desenvolvimento dos conceitos que norteiam a análise, apresentação dos dados do perfil da CGU, monitoramento da página no Facebook e discussão sobre as entrevistas, que está dividido em: entrevista com a assessoria de comunicação e entrevista com a equipe técnica. Por fim, a conclusão resgata a pergunta inicial, acerca das relações entre atuação da CGU nas redes sociais ( Facebook) e as possibilidades de ampliação da divulgação de informação, conforme preconizado pela Lei 12527/2011( Lei de Acesso à Informação) e suas relações com a politização do debate, a democracia e o fortalecimento de uma cultura da informação.

\section{APRESENTANDO CONCEITOS}

O advento da tecnologia é um fato que vem mudando a forma de agir, se relacionar e pensar as redes de interações entre as pessoas e isso não é diferente quando se pensa o Estado. Pensar o Estado e sua relação com a tecnologia é desafiador, pois ainda é um campo pouco estudado, o que enseja renovados estudos no campo.

No Brasil, as discussões sobre a atuação dos governos no âmbito virtual iniciou-se com a reforma do Estado, que buscava uma maior eficiência e aproximação do Estado com os cidadãos e para isso houve um redesenho da gestão através de várias medidas, entre elas o uso de tecnologia de informação. As consequências dessas medidas são a alteração da configuração da gestão do Estado, que deixou de ser um Estado monolítico e essencialmente hierárquico fundado nos procedimentos formais para constituir-se em uma gestão descentralizada e delegativa de funções ${ }^{1}$. (Matias-Pereira,2008, p.20)

Entendendo o uso da internet como uma tendência da nova gestão pública e uma complementação ao modelo burocrático weberiano, chama a atenção o fato de como o Estado

\footnotetext{
${ }^{1}$ - MATHIAS-PEREIRA, J. Manual de gestão pública. $1^{\circ}$ ed. São Paulo: Atlas, 2008, p . 20
} 
tem se apropriado das redes sociais como ferramenta para sua atuação. A pergunta que cabe diante desta constatação é: esse uso tem proporcionado uma transparência e enriquecimento da prática democrática? Ele tem proporcionado o fortalecimento de uma cultura da informação?

Ao se discutir esse entrelaçamento entre internet, Estado e participação se faz necessário à compreensão acerca do que é o governo eletrônico. O conceito de governo eletrônico pode ser entendido de maneiras várias. Nesse artigo entende-se governo eletrônico como:

Governo eletrônico é uma infra-estrutura única de comunicação compartilhada por diferentes órgãos públicos a partir da qual a tecnologia da informação e da comunicação é usada de forma intensiva para melhorar a gestão pública e o atendimento ao cidadão. Assim, o seu objetivo é colocar o governo ao alcance de todos, ampliando a transparência das suas ações e incrementando a participação cidadã. $^{2}$

A visão de governo eletrônico varia conforme a literatura usada como referência, mas as diferentes vertentes tem em comum o reconhecimento de que o governo eletrônico reside na atuação dos governos em âmbito virtual para aperfeiçoamento da gestão pública.

A participação social pode ser entendida como o engajamento, o ato de opinar, escolher e debater sobre assuntos de interesse público o que impulsiona, em geral, ações coletivas. As ações coletivas podem ser entendidas como decisões tomadas em grupo e que são postas em práticas, tais como abaixo-assinados, manifestações e outras formas de agir.

Ao se pensar o governo eletrônico, deve-se atentar para a relação entre governo eletrônico e participação. Nesse contexto parece haver um potencial democrático e de participação que as redes sociais e outros programas de governo trazem para a sociedade civil. 0 problema que se investiga no artigo, destaca a seguinte questão: a participação/ativismo identificado nas redes sociais proporcionam, ou não, um incentivo a cultura de informação e politização por parte dos usuários? Uma das visões majoritária sobre esse potencial democrático é bem expresso por Sampaio:

\begin{abstract}
A participação qualificada de uma parte significativa dos indivíduos e organizações da esfera civil está relacionada a uma cultura cívica e a uma cultura de política de participação, questões muito mais complexas de serem desenvolvidas e promovidas se comparadas à provisão de ferramentas digitais. Destaca-se, entretanto, que se trata de algo importante, senão vital, que tais canais sejam abertos e mantidos para as ocasiões em que o cidadão desejem se manifestar a respeito daqueles que os representam ou de seus interesses e
\end{abstract}

\footnotetext{
${ }^{2}$ ROVER, Aires José. Introdução ao governo eletrônico: in governo eletrônico e inclusão digital. Rover, Aires José (org.). Florianópolis: Fundação Boiteux, 2009, p.95. 
necessidades. Isso, evidente, se realmente deseja-se mitigar alguns dos déficits das democracias representativas contemporâneas. ${ }^{3}$

Percebe-se, na visão de Sampaio, que o ambiente virtual apresenta um importante potencial para a ampliação da participação social, porém a participação virtual é o reflexo de uma cultura prévia de participação e de interesse em temáticas de interesse público, logo, a normatização legal, cujo exemplo mais paradigmático é o da Lei de Acesso à Informação, que garantem o direito ao acesso à informação e apresenta um conjunto de procedimentos para sua operacionalização, não necessariamente garante uma cultura de cidadania ativa e de participação, requisitos fundamentais para a efetivação do direito prescito pela lei. Ao lado da ideia de participação/ativismo é importante compreender o conceito de transparência ativa e passiva. Segundo a CGU:

A iniciativa do órgão público de dar divulgação a informações de interesse geral ou coletivo, ainda que não tenha sido expressamente solicitada, é denominada de princípio da transparência ativa ${ }^{4}$

Ou seja, a transparência ativa é aquela em que as instituições públicas se propõe a divulgar as informações importantes sem o pedido prévio do cidadão. Essa forma de transparência abre possibilidade de interação e ampliação da prestação de contas, pois ela pode guardar uma relação com as práticas de governo eletrônico. Entretanto, a forma de transparência passiva se caracteriza pela maior atuação do usuário. A CGU entende a transparência passiva como:

A transparência passiva se dá quando algum órgão ou ente é demandado pela sociedade a prestar informações que sejam de interesse geral ou coletivo, desde que não sejam resguardadas por sigilo ${ }^{5}$

Ao problematizar a ideia de Sampaio, que destaca a necessidade de uma cultura prévia de participação como essencial para a viabilização da participação virtual, pode-se entender que as práticas articuladas pela transparência passiva deve ser estimulada para uma construção de

\footnotetext{
${ }^{3}$ SAMPAIO, Rafael Cardoso. Participação política e os potenciais democráticos da internet. Porto Alegre: debates,2010. p.48.

${ }^{4}$ BRASIL. Controladoria Geral da união. Manual da lei de acesso a informação para estados e municípios. Brasília/2013. Disponível em: http://www.cgu.gov.br/Publicacoes/transparencia-publica/brasiltransparente/arquivos/manual_lai_estadosmunicipios.pdf ${ }^{5}$ BRASIL. Controladoria Geral da união. Manual da lei de acesso a informação para estados e municípios. Brasília/2013. Disponível em: http://www.cgu.gov.br/Publicacoes/transparencia-publica/brasiltransparente/arquivos/manual_lai_estadosmunicipios.pdf
} 
uma cultura de informação. Nesse universo, o trabalho da CGU tem sido a conciliação entre os dois tipos de transparência, na intenção de obter maior publicidade e envolvimento com a sociedade civil.

Outro ponto muito importante ao se discutir a ação da Administração Pública nas redes sociais é a relação entre governo eletrônico e governança. O conceito de governança pode ser entendido de várias maneiras. Para Rosenau,

Governança é um fenômeno mais amplo que governo; abrange as instituições governamentais, mas implica também mecanismos informais, de caráter nãogovernamental, que fazem com que as pessoas e as organizações dentro da sua área de atuação tenham uma conduta determinada, satisfaçam suas necessidades e respondam às suas demandas. ${ }^{6}$

Entende-se governança como uma relação de via de mão dupla entre Estado e sociedade civil, onde os mecanismos virtuais são artefatos que potencializam a boa governança. É através da capilaridade que o governo eletrônico proporciona que a governança seja expandida, no sentido de ser mais ampla e efetiva.

E, por fim, um conceito importante a ser retomado na discussão final do trabalho referese à cultura da informação. Recentemente, os Estado tem buscado ampliar as formas de dar transparência à sua ação. Assim, a ideia de publicizar os negócios estatais vem ganhando força nas democracias modernas. Fruto desta perspectiva é a instituição do direito à informação. Nesse sentido, o direito à informação está relacionado maior visibilidade e compreensão da ação pública, consistindo em instrumentos, os quais apontam uma preocupação com a transparência e com a divulgação da atuação do Estado, ligando-se a cultura da informação na medida em que favorecem a ampliação do controle social. ${ }^{7}$

Assim, o Direito à Informação vem sendo incorporado às constituições nacionais e, conforme, Mendel,

\footnotetext{
${ }^{6}$ ROSENAU, James N. Governança, Ordem e Transformação na Política Mundial. In: Rosenau, James N. e Czempiel, Ernst-Otto. Governança sem governo: ordem e transformação na política mundial. Brasília: Ed. Unb e São Paulo: Imprensa Oficial do Estado, 2000. pp. 11-46

7 - FARRANHA,Ana Claudia; OLIVEIRA, Rafael Oliveira e RAMINELLI, Francielle Puntel. Lei de Acesso à Informação (Lei. no. 12.527/2011) e administração pública: direito à informação, proteção à intimidade e desafios para a regulação ( o caso do Ministério da Saúde). In: Tania Margarete Mezzomo Keinert, Flavia Mori Sarti, Carlos Tato Cortizo e Silvia Bastos (orgs.). Proteção à Privacidade e Acesso às Informações em Saúde: Tecnologias, Direitos e Ética. Editora do Instituto de Saúde. São Paulo, 2015
} 
Nos últimos anos, houve uma verdadeira revolução no direito à informação, que é comumente compreendido como o direito de acesso à informação mantida por órgãos públicos. Enquanto, em 1990, apenas 13 países haviam adotado leis nacionais de direito à informação, hoje mais de 70 dessas leis já foram adotadas em nível global, e estão sendo consideradas ativamente em outros 20 ou 30 países. Em 1990, nenhuma organização intergovernamental reconhecia o direito à informação. Agora, todos os bancos multilaterais de desenvolvimento e uma série de outras instituições financeiras internacionais adotaram políticas de divulgação da informação. Em 1990, havia uma visão predominante do direito à informação como uma medida de governança administrativa, ao passo que hoje este direito é cada vez mais considerado como um direito fundamental ${ }^{8}$.

Com base nestes conceitos é que se analisa a atuação da CGU no Facebook e eles serão retomados na conclusão do presente artigo, auxiliando nas respostas apontada por essa pesquisa.

\section{MONITORAMENTO DA PÁGINA OFICIAL NO FACEBOOK DA CGU}

A página da CGU no Facebook foi fundada no dia vinte e cinco de janeiro de dois mil e onze. Atualmente conta com cerca de 218 mil seguidores e tem avaliação de 4,5 em 5 nas opiniões dos internautas, registrado pela própria página.

O monitoramento ocorreu no mês de maio de dois mil e quinze, por ser o mês em que a LAl completou 3 anos e, por isso, consequentemente obteve um aumento em postagens relacionadas a lei. 0 acompanhamento da página teve como intuito captar as principais pautas discutidas, a interação entre a instituição e internautas (no sentido de respostas obtidas, curtidas, compartilhamentos e comentários) e problematizar postagens relacionadas à Lei de Acesso à Informação.

A metodologia usada reside na somatória da técnica de observação direta e da análise de conteúdo. O uso de entrevistas semi-estruturadas e a revisão da literatura permitiu a construção de um arcabouço teórico para a investigação.

A coleta de dados realizada no Facebook seguiu a metodologia da observação direta. Segundo Cervo e Bervian (2002, p. 27), “observar é aplicar atentamente os sentidos físicos a um amplo objeto, para dele adquirir um conhecimento claro e preciso”. Sem a observação, o estudo seria apenas “[...] à simples conjetura e simples adivinhação”. Partindo desse pressuposto,

8 - MENDEL, Toby. Liberdade de informação: Um estudo de direito comparado. $2^{\circ}$ ed. Brasília: UNESCO,2009, p.03 
realizou-se a observação das postagens, no período indicado. Observou-se os temas tratados, 0 uso de links e hashtags e compartilhamento de publicações e comentários.

A análise dos dados seguiu a metodologia de analise de conteúdo, que conforme Bardin (1991, p.7), trata-se de como um conjunto de técnicas de análise das comunicações, que utiliza procedimentos sistemáticos e objetivos de descrição do conteúdo das mensagens. A análise de conteúdo é descritiva e quantitativa, com problematização dessas postagens.

No mês monitorado ocorreram 48 postagens, sendo 33,3\% com menção direta a Lei de Acesso à Informação; com uma média de 1,6 postagens por dia. Observou-se um constante uso de links e imagens interativas e uma ênfase grande em assuntos relacionados com a transparência (cerca de $25 \%$ das postagens).

Esse tópico será dividido em: panorama geral das postagens, discussão sobre a interação virtual e os trabalhos sobre a LAl durante o mês investigado.

\subsection{Panorama geral das postagens}

As postagens da CGU no facebook tem, em geral, uma característica de postagens educativas e interativas. São postagens com frases curtas, claras e objetivas. Como ressaltado na entrevista com o analista de redes sociais, as postagens tem o objetivo de atrair os internautas de forma interativa e que a mensagem principal chegue ao cidadão de maneira clara. Para isso usam-se diversos recursos, tais como: imagens, hashtag, links e postagens com conteúdo diverso (cursos, reflexões e notícias sobre temáticas diversas).

Entendendo o ato de curtir, compartilhar e comentar como um ato que legitima e que fortalece o debate sobre temas interesses público pode-se inferir que a página da CGU apresenta um bom índice de interação com a sociedade civil. As postagens contam com uma média de 538 curtidas,488 compartilhamentos e 29 comentários de internautas, lembrando que existe uma grande diferença dessa quantidade, conforme o tema que a postagem aborda. Os temas relacionados à corrupção são os que mais logram interações.

Das quarenta e oito postagens observadas durante o mês de maio, todas contavam com o uso de imagens que continham frases diretas ou esquemas explicativos sobre programas e ações governamentais, exemplificada na imagem a seguir: 


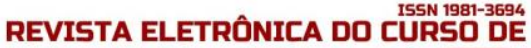

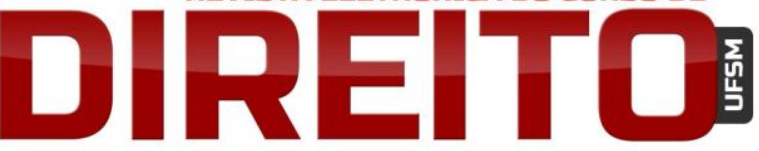

ADMINISTRAÇÃO PÚBLICA, DIREITO E REDES SOCIAIS: O CASO DA CGU NO FACEBOOK

ANA CLÁUDIA FARRANHA LEONARDO TADEU DOS SANTOS

Imagem 1- Cartilha para procedimento para realização de pedidos da LAI

\section{$\operatorname{cst}$}

CGU - Controladoria-Geral da União (oficial)

\#LeideAcesso: E você, já está participando dessa "corrida" para garantir a seu direito constitucional de acesso à informação? :-:

A LAl é uma peça fundamental para o incremento da transparência pública e o cidadão bem informado tem melhores condiç̃es de conhecer

e acessar outros direitos essenciais, como saúde, educação e beneficios sociais.

Siga as casas de acesso, saiba como fazer o seu pedido ao Governo

Federal e participe dessa maratona democrática em que t... Ver más

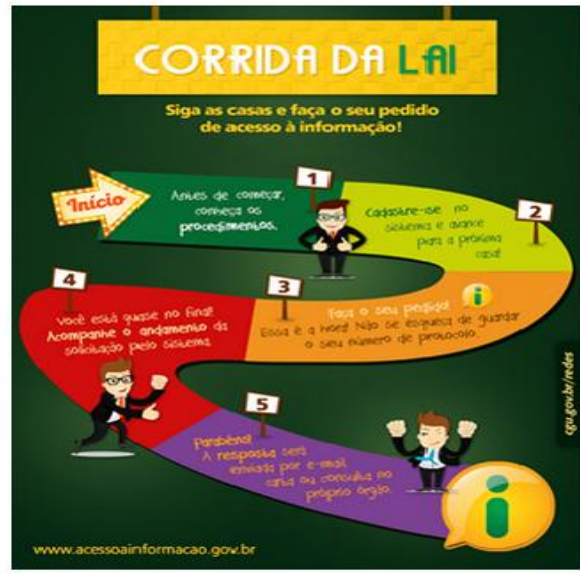

Fonte: Pagina oficial da CGU no Facebook (maio/2015)

Essa imagem demostra como o uso de cartilhas explicativas pode ajudar o cidadão a obter informações em programas, realizar pedidos, fazer denúncias e diversos outros serviços que estão previstos no texto legal.

O uso de links é outro recurso largamente usado pela CGU, 94\% das postagens contavam com links que direcionavam os internautas a páginas ou sítios online em que continham mais informações sobre o assunto contido no post. 0 uso desses links está compreendido no trabalho da instituição em fazer a chamada e instigar o usuário a pesquisar e aprofundar mais sobre as questões apresentadas. No geral esses links reportam a sítios de instituições que prestam serviços públicos ou a sites de jornalismo que divulgam notícias relacionadas ao trabalho da CGU.

As hashtags, apesar de serem mais populares na rede social Twitter, vêm sendo usada pela CGU no Facebook. $\mathrm{O}$ uso de hashtags tem como finalidade a filtragem de assuntos, temas e discussões específicas É uma espécie de codificação em que a procura e o direcionamento a temas específicos é facilitado. A grande maioria das hashtags usadas está relacionada a temas como transparência, educação, curso e a lei de acesso a informação. 


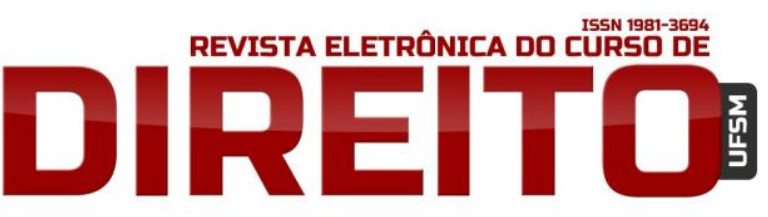

ADMINISTRAÇÃO PÚBLICA, DIREITO E REDES SOCIAIS: O CASO DA CGU NO FACEBOOK

ANA CLÁUDIA FARRANHA LEONARDO TADEU DOS SANTOS

Num panorama geral das postagens, é importante ressaltar o destaque de postagens sobre ações, incentivos e discussão sobre transparência. A maioria das postagens realizadas está ligada ao princípio da publicidade e a transparência. Um exemplo, bastante ilustrativo é dado pela imagem a seguir:

Imagem 2- postagem sobre transparência

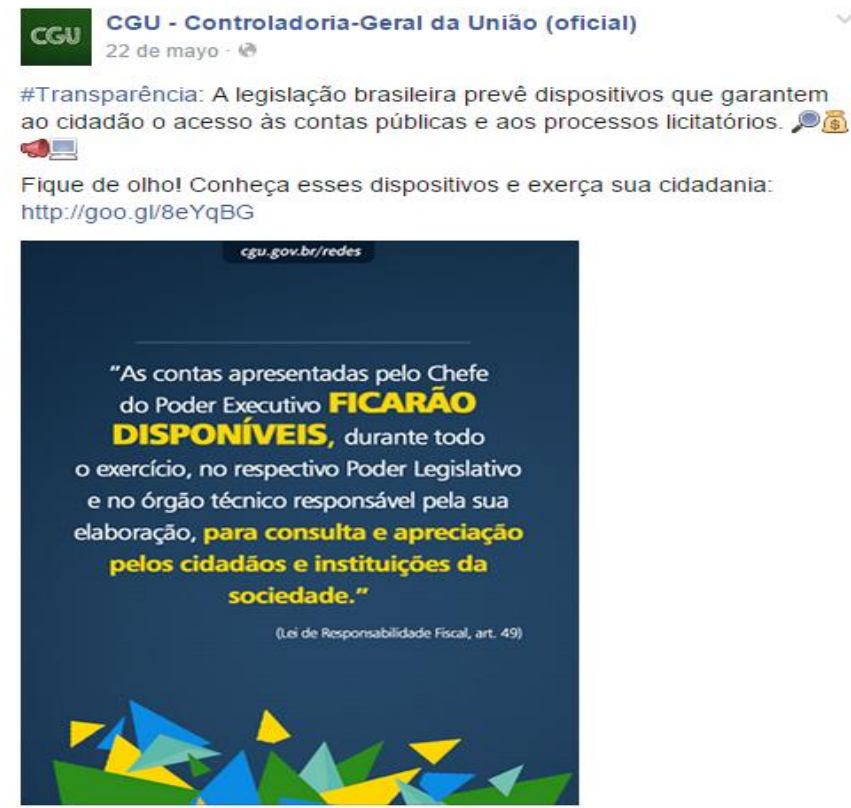

Fonte: Página oficial da CGU no Facebook (maio/2015)

Essas imagens, normalmente, fazem referência a leis que asseguram a transparência, como a Lei de Responsabilidade Fiscal (lei $n^{\circ}$ 101/2000), a Lei de Acesso à Informação (lei $\left.\mathrm{n}^{\circ} 12.527 / 2011\right)$ e outras.

Um grande avanço da CGU é o oferecimento e divulgação de cursos online. São cursos de pouca duração, gratuitos e sobre temas de interesse público. Esse tipo de ação é uma forma de aumentar a publicização e de aperfeiçoar a interação virtual, que será discutida no próximo tópico. A seguir um exemplo da divulgação de curso: 


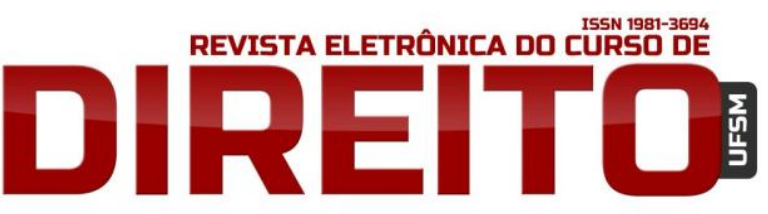

ADMINISTRAÇÃO PÚBLICA, DIREITO E REDES SOCIAIS: O CASO DA CGU NO FACEBOOK

ANA CLÁUDIA FARRANHA LEONARDO TADEU DOS SANTOS

Imagem 3- imagem sobre cursos oferecidos pela CGU
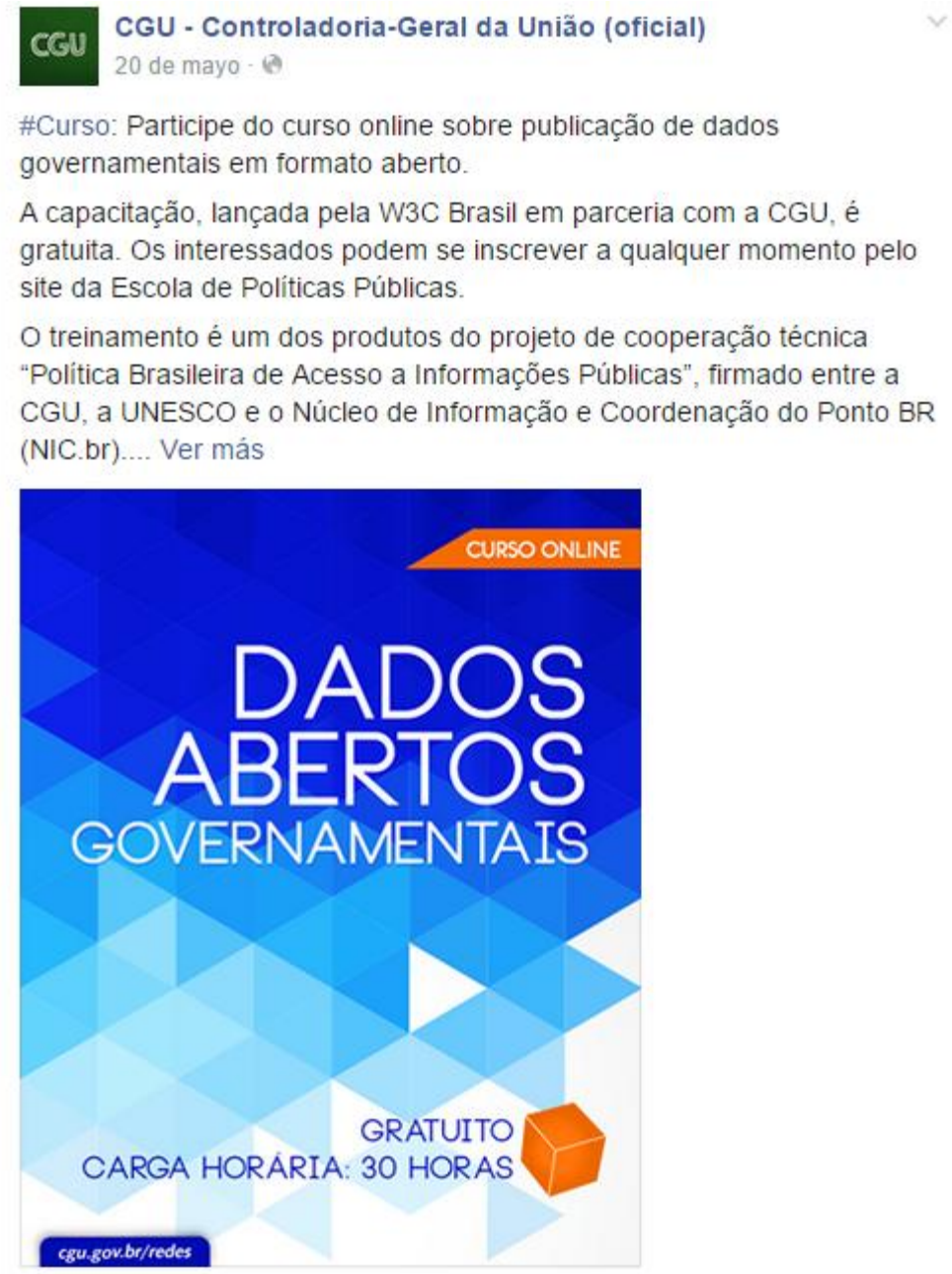

Fonte: Página oficial da CGU no Facebook (maio/2015)

Esses cursos são formas de ampliar espaços com uma perspectiva de informar e até mesmo de dialogar com a sociedade civil.

O monitoramento realizado por esse trabalho captou muitas postagens com conteúdo políticos e informacionais; entretanto notou-se baixa interação com os usuários. Existe muito volume, no sentido de existir muitas curtidas, comentários e compartilhamentos e pouca resposta efetiva da instituição. Todavia essa baixa taxa de resposta não deslegitima o trabalho de divulgação e capilarização de canais com temas de interesse público. 0 grande potencial desses canais é a divulgação e chamamento aos internautas a participarem e ocuparem espaços públicos. 


\section{INTERAÇÃO VIRTUAL}

Um dos tópicos importantes desse artigo é entender como se dá a interação virtual entre internautas e o órgão público, pois essa interação é a ponte entre a administração pública e os cidadãos, ou seja, é essa interação que nos possibilita analisar como se dá a participação no âmbito virtual, bem como identificar em que medida essa interação está relacionada a práticas mais democráticas de governo eletrônico. ${ }^{9}$

Dentre os princípios do direito à informação, segundo Mendel $^{10}$, princípio da máxima divulgação, obrigação de publicar, promoção de um governo aberto, limitação das abrangências das exceções, procedimentos que facilitem o acesso, dos custos, reuniões abertas, precedência e proteção dos denunciantes. Percebemos que a CGU tem avançado na efetivação desses princípios. Todavia o simples direcionamento por esses princípios, ainda que garantam uma maior transparência, não garante o crescimento de uma cultura de informação e politização.

Uma forma interessante de interação que a instituição vem se esforçando para realizar referem-se as respostas diretas, através dos comentários no Facebook. Dentre os 1387 comentários 70 obtiveram respostas, ou seja, apenas $5 \%$ dos comentários foram respondidos pela instituição. Isso mostra que a interação, por mais que tenha avançado, ainda se mostra fraca. Ainda sobre esses comentários é de extrema importância ressaltar que muitos comentários de internautas são fora de contexto ou não fala sobre o assunto em pauta. Os comentários da instituição são sempre pontuais, objetivos e têm um caráter de imparcialidade, como ilustra a imagem a seguir:

\footnotetext{
9 - PINHO, José Antônio Gomes de. Investigando portais de governo eletrônico de estados no Brasil: muita tecnologia, pouca democracia. Revista de Administração Pública, v. 42, n. 3, p. 471-493, 2008.

10 - MENDEL, Toby. Liberdade de informação: Um estudo de direito comparado. $2^{\circ}$ ed. Brasília: UNESCO,2009.
} 
Imagem 4 - respostas da CGU aos internautas

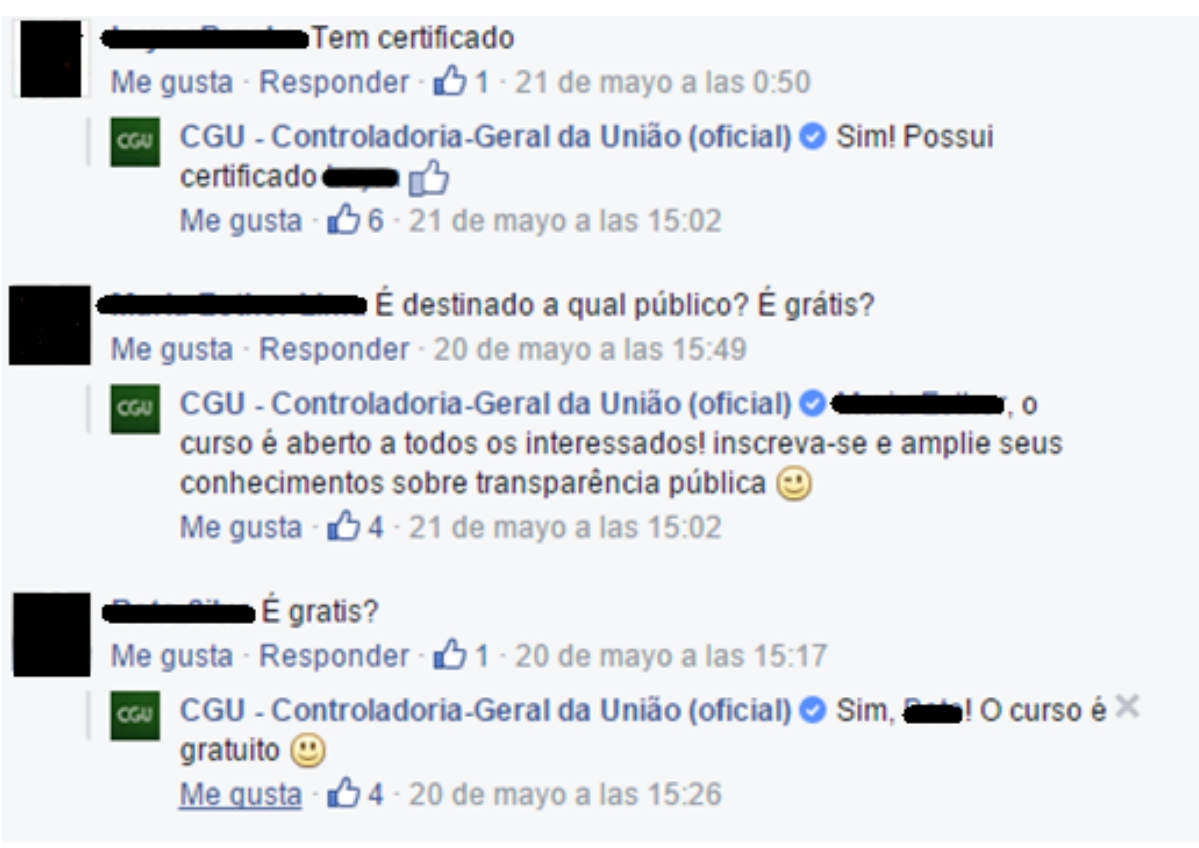

Fonte: Pagina oficial da CGU no Facebook (maio/2015)

Durante a entrevista a assessoria de comunicação informou da dificuldade em responder a todas as demandas vindas do Facebook e nos revelou que as respostas são direcionadas a dúvidas mais frequentes.

Um dos recursos usado pela CGU para dimensionar as respostas aos usuários e o nível de interação, segundo a assessoria de comunicação, são indicadores de engajamento. Esses indicadores demonstram a relação de entre usuários e interações (curtidas, compartilhamentos e comentários) realizados. Esse indicador é mensurado de 0 a 1, onde mais próximo de 1 maior é o engajamento. A sua formula matemática é: 


$$
x=\frac{d y}{d x}
$$

onde: $x=$ grau de engajamento $($ de 0 a 1$)$

$d y=$ número de interações ( curtidas, compartilhamentos e comentários)

$d x=$ número de usuários $(218.000)$

Essa pesquisa elaborou os seguintes cálculos, com base nos dados colhidos no período de monitoramento:

Quadro 1: Número de interações

\begin{tabular}{|l|l|l|l|l|}
\hline & Curtidas & Compartilhamentos & Comentários & $\begin{array}{l}\text { Resposta em } \\
\text { comentários }\end{array}$ \\
\hline $\begin{array}{l}\text { Quantidade } \\
\text { numericas }\end{array}$ & 25.809 & 23.428 & 13.357 & 70 \\
\hline
\end{tabular}

Fonte: autoria própria

Ao se realizar esse cálculo obteve-se o índice de 0,12 nas curtidas e 0,11 nos compartilhamentos e apenas 0,06 em comentários e 0,032 em respostas em comentários pela instituição. Esses dados revelam que a interação tem se dado mais por ações que legitimam (curtir e compartilhar) do que por ações que envolvem e criam espaços de debates (comentários e respostas a comentários). Os números dizem também que a interação se encontra a níveis baixos, pois as curtidas (onde ocorre maior interação) conta com apenas 0,12 numa escala de 1 . Observe o gráfico: 


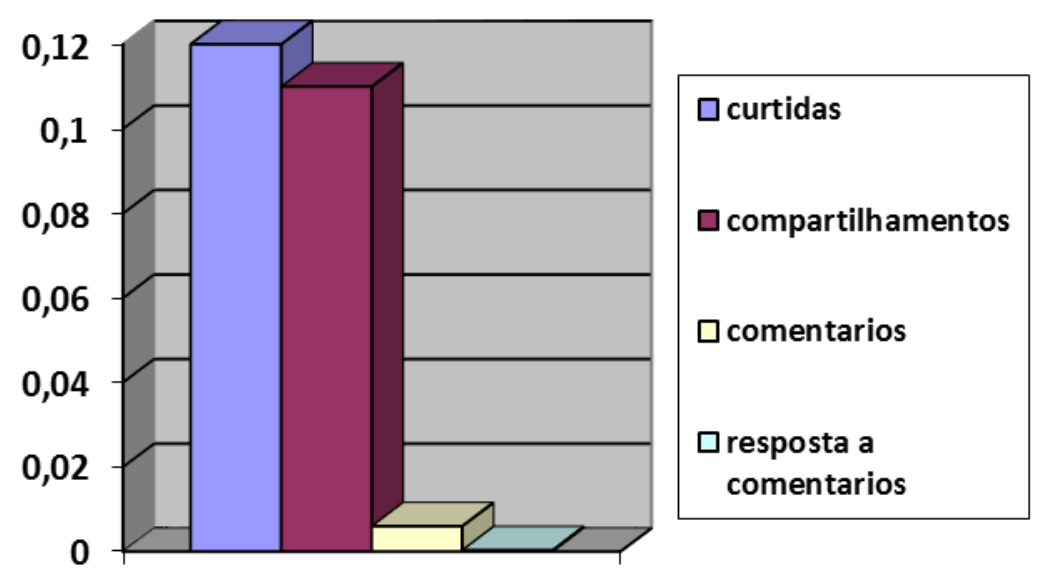

Fonte: autoria própria

A interação tímida abre espaço, segundo Farranha ${ }^{11}$, para a discussão da necessidade da Administração Pública ampliar esses espaços para uma perspectiva dialógica. A ampliação desses espaços deve ser pensada de forma a abarcar suas diversas variáveis como a forma de processar as demandas, aparato burocrático preparado, público alvo, obstáculos relacionados à inclusão digital entre outras observações.

Um dos grandes desafios da atuação do governo nas redes sociais é tornar as páginas virtuais em locais de diálogo entre os atores e não apenas ter um caráter de informar, ou seja, evitar o uso como apenas meio de divulgar a informações. O que o trabalho demonstra é que não basta apenas apresentá-la, mas, é preciso discuti-la. Entretanto tem se observado um forte caráter informacional e pouco caráter de interação direta.

A equipe técnica e de comunicação ciente disso, informou que existe a intenção de ampliar esse diálogo e que muitas reclamações e sugestões de internautas são discutidas e pautadas em reuniões dentro da instituição, porém, por ser algo novo no governo, não está padronizada a forma de interagir.

É importante lembrar que a interação não se dá somente por respostas escritas, e sim por conteúdo e formas de atrair o internauta, nesse quesito a CGU tem se mostrado eficiente ao

\footnotetext{
${ }^{11}$ - FARRANHA, Ana Claudia et al. Administração pública e redes sociais (Facebook e Twitter): Analise de casos selecionados. Revista Negócios em Projeção; v.5, n. 1. Brasília, 2014.
} 
lançar mão de recursos midiáticos como cartilhas, cursos, reflexões, imagens e links que são formas de tornar a interação mais efetiva e de conectar o uso das redes sociais com a possibilidade de efetivar o direito à informação, inscrito no artigo $5^{\circ}$, incisos IV, X, XII, XIV, XXXIII, XXXIV ( alínea “b”), LX, LXXII, bem como artigo $37^{\circ}$ parágrafo $3^{\circ}$, II, artigo 93, IX, artigo 216, paragráfo $2^{\circ}$., artigo $22^{\circ}$, caput e parágrafos.

De forma geral, nota-se que a interação virtual é essencial para uma boa implementação da Lei de Acesso à Informação, pois ela pode proporcionar um canal para transparência ativa e pode politizar os internautas em torno das questões públicas. É indiscutível o avanço no uso de tecnologias virtuais nos últimos dez anos pelos órgãos públicos. Entretanto, é preciso pensar novos arranjos de interação entre Estado e sociedade civil.

\section{A VISÃO DO ORGÃO: ENTREVISTAS REALIZADAS}

Com base na metodologia descrita, foram realizadas duas entrevistas. A primeira entrevista foi realizada no dia doze de maio de dois mil e quinze com o analista de redes sociais da assessoria de comunicação. A segunda entrevista foi realizada no dia vinte e seis de maio de dois mil e quinze com duas analistas de finanças e controle da equipe técnica de transparência, responsáveis pela Lei de Acesso à Informação.

As duas entrevistas permitiram conhecer melhor como o órgão tem pensado, planejado e executado suas atividades no mundo virtual e qual o impacto, na opinião deles, dessa atuação para a cultura de informação e politização dos navegantes da internet.

Esse tópico será dividido em três tópicos: entrevista com a assessoria de comunicação, entrevista com a equipe técnica e uma consideração final sobre as entrevistas.

\subsection{Entrevista com a assessoria de comunicação}

A entrevista com o analista de redes sociais foi estruturada por um questionário previamente montado cujas temáticas referiam-se a

a) Experiência do órgão em redes sociais

b) Desenvolvimento do trabalho e o uso das redes sociais pelo governo 
c) Relação entre uso de redes sociais e promoção do acesso à informação pelos órgãos governamentais

d) Avaliação da ação governamental nas redes sociais

e) Potencialidades que as redes sociais apresentam para uma estratégia de ampliação da participação popular.

Esses temas foram debatidos de e se deu de forma livre e aberta ao diálogo sobre temas relacionados à atuação da instituição no âmbito virtual.

A assessoria de comunicação é uma secção, relativamente, nova na instituição e a atuação nas redes socias pela CGU teve início em janeiro de dois mil e onze, por influência do então Ministro Jorge Hage. Os trabalhos nas redes sociais começaram de forma tímida, divulgado apenas questões pontuais e hoje conta com perfis em várias redes sociais com um número expressivo de seguidores. 0 crescimento da atuação online foi acompanhado pelo crescimento do aparato burocrático responsável por esse tipo de serviço. A equipe que iniciou os trabalhos com apenas um funcionário, hoje conta com quatro pessoas e com reconhecimento por outras repartições. Essa ação de crescimento se deu pelo entendimento de que a CGU como órgão de transparência deveria estar atuando nas redes sociais, como forma de maior promoção da transparência governamental.

Sendo essas ferramentas virtuais vistas como formas de ampliação da democracia, o Analista ressaltou que essa atuação é pensada de forma a ser o mais claro e próximo dos internautas, pois, em suas próprias palavras, a instituição tem que atuar como usuários da rede; ou seja, ocorrer a partir da horizontalidade e não de forma hierárquica. Essa forma de interação a interação tem que é crucial para alcançar uma das metas da CGU que é que esse material publicado seja capaz de sanar dúvidas, publicizar, informar e manter interações com a população.

Sobre o potencial do uso sistemático da internet pela instituição no intuito de politização e ampliação da participação popular, o analista reconheceu que não existe um aparato técnico robusto o bastante para acompanhamento de tais interações e que o papel da CGU reside, basicamente, na divulgação de conteúdo e materiais que servem de instrumental para os cidadãos se localizarem e procurar se aprofundar em assuntos de interesse público.

A mensuração acerca de quanto as publicações no Facebook do órgão possibilitam identificar se elas alcançam a população e se a população está usufruindo dessas informações, é de difícil obtenção. Uma forma de mensurar é através de indicadores de engajamento, onde a assessoria de comunicação faz a relação matemática entre a quantidade de usuários inscritos na 
página e a quantidade de interação (curtidas, compartilhamentos e comentários). Essa forma de mensurar se mostra mais efetiva do que apenas indicadores quantitativos de número de seguidores, curtidas, compartilhamentos, comentários e hashtags, pois o indicador de engajamento traz a informação sobre a legitimidade e como tem se desenvolvido o diálogo virtual entre governo e sociedade civil.

A assessoria tem a política de responder todas as dúvidas e questionamentos possíveis, com a barreira de uma pequena estrutura para tamanha demanda, sendo respondidos questionamentos e dúvidas mais frequentes.

A entrevista foi finalizada com um reforço da preocupação do governo em, cada vez mais, lançar mão de recursos digitais para a interação com a sociedade civil. Apesar dos enormes desafios, como a exclusão digital, e a falta de clareza de como se pode trabalhar essa interação na hora de realizar políticas públicas, é preciso reconhecer a importância desse trabalho e de como ele vem crescendo exponencialmente desde a reforma do Estado Brasileiro. Ainda foi destacado que a execução da LAl pode ser muito beneficiada com a sua divulgação e fomentação de participação através das redes sociais.

\subsection{Entrevista com a equipe técnica}

A entrevista com a equipe técnica foi realizada com duas analistas de finanças e controle e foi guiada por um roteiro, cujas temáticas se assemelhavam as da primeira entrevista, com acréscimo de questões específicas sobre a Lei de Acesso à Informação, e de forma aberta ao diálogo sobre assuntos relacionados ao trabalho da equipe.

A equipe técnica de transparência, responsável pelo acompanhamento da Lei de Acesso à Informação (LAl-Lei no 12.527/2011), executa trabalhos relacionados a finanças, controle e monitoramento da execução da lei. A equipe conta com uma grande heterogeneidade de funcionários formados em diversas áreas; tais como: contadores, estatísticos, profissionais da comunicação e de tecnologia da informação. As analistas ressaltaram essa heterogeneidade de forma muito positiva, pois isso é visto como uma forma que ajuda a pensar a transparência de forma mais ampla e democrática.

Durante a entrevista, observou-se que muitos aspectos que foram observados na conversa com a assessoria de comunicação, se apresentaram novamente. Essas questões referem-se à elaboração de materiais de fácil entendimento e com conteúdos capazes de 
contribuir para a divulgação da LAl e de ações voltadas para maior transparência, destacando como o clima organizacional contribui para a efetivação desse trabalho.

O clima organizacional positivo entre as duas equipes é um fator essencial para o desenvolvimento de ações que visem o maior acesso e transparência através das redes sociais digitais; uma das analistas reforçou a ideia de que essas ações são pensadas de uma forma em que o governo entende esse canal como um meio de comunicação e não apenas de divulgação; sendo esse pensamento predominante na equipe de assessoria de comunicação.

Ainda sobre a produção de conteúdo e as formas de trabalhar as postagens nas redes sociais, a equipe reconheceu que a CGU exerce um papel de chamamento. Esse papel consiste em atrair o cidadão para o aprofundamento do debate em outros ambientes e órgãos. Trata-se de uma forma indireta de fomentar a politização e a cultura de informação. Isso ocorre, pois a CGU não tem o papel de aprofundar o debate, e sim instigar e orientar a sociedade civil aonde sobre os canais onde a informação pode ser encontrada.

A discussão sobre a cultura de informação, segundo as entrevistas, é também um desafio interno. Segundo os atores entrevistados, existe uma barreira muito grande dentro dos órgãos públicos em relação a projetos e trabalhos com objetivo de ampliar a transparência, isso ocorre porque muitos funcionários veem a transparência como um processo muito trabalhoso e não necessário. Entretanto, ressaltou-se que é necessário pensar formas de enfrentar a barreira interna para poder trabalhar a transparência e seus obstáculos externos.

Também vale ressaltar o reconhecimento dos próprios funcionários acerca do trabalho da CGU, o qual tem um forte potencial de ampliar a participação social no ambiente virtual; e que apesar de ser uma modalidade nova de participação, muitos recursos têm sido utilizados para o aperfeiçoamento dessa nova forma de se fazer proporcionar mais democracia.

A entrevista foi finalizada com uma explanação geral sobre a ascensão do governo eletrônico e como a atuação online da CGU tem obtido reconhecimento. 0 fato de a instituição trabalhar com temas relacionados à corrupção, transparência e campanhas para maior acessibilidade a serviços públicos o uso das redes sociais tem logrado mais dinamismo e legitimidade aos seus trabalhos. 


\subsection{Considerações sobre as entrevistas}

As duas entrevistas tiveram como intuito perceber como a CGU tem desenvolvido a noção de governo eletrônico e aplicado princípios, como publicidade e transparência, os quais têm nas redes sociais uma possibilidade de efetivação.

Foram entrevistas duas equipes chaves no processo de publicização, na internet, dos conteúdos do órgão. A equipe técnica que direciona os principais temas abordados na internet e a assessoria de comunicação que trabalha a informação que será divulgada aos cidadãos.

As entrevistas fornecem elementos para compreender o cenário de atuação governamental no âmbito das redes sociais. A presença do governo em redes sociais é uma novidade para a Administração Pública e junto com ela veio a expectativa de ampliação da participação social. Os funcionários entrevistados mostram como os gestores têm pensado e trabalhado esse novo canal e quais têm sido os principais desafios e conquistas alcançadas a partir desta atuação.

Neste universo, pode-se perceber como as práticas mais recorrentes do órgão, tais como: combate à corrupção, auditoria publica, corregedoria, ouvidoria, promoção da transparência, acesso a informação, assistência diretamente a Presidência da República quanto aos assuntos citados anteriormente estão sendo desenvolvidas com o auxílio das redes sociais e como se tem estruturado esse trabalho nessa plataforma de interação.

Com as informações obtidas, é possível inferir que a CGU tem se preocupado com a ampliação da atuação online, principalmente no que concerne ao uso do Facebook, porém ainda existem grandes obstáculos. Dentre esses obstáculos, pode-se destacar o pequeno número de funcionários para desenvolver o uso mais frequente e contínuo das redes sociais, uma atuação muitas vezes descontínua e uma barreira imposta pelos órgãos em relação a ampla divulgação de informações capaz de promover uma verdadeira cultura da transparência; o que dificulta a fomentação de uma politização e uma prática de ampla divulgação da informação. Todavia, merece destaque, os avanços da instituição no aumento exponencial de seus trabalhos relacionados ao combate à corrupção e maior transparência. 


\section{POSTAGENS SOBRE A LEI DE ACESSO A INFORMAÇÃO}

Esse tópico visa debater sobre as postagens que contém menção direta a Lei de Acesso à Informação. O monitoramento da página ocorreu no mês em que a LAl completou três anos e por isso percebeu-se um trabalho voltado pra divulgação e informações sobre a lei.

Das 70 postagens realizadas, 16 continham menção direta a LAl, seja menção através de hashtag, imagens ou textos que falassem especificamente sobre a lei. O Facebook da CGU é um portal em que se divulga muito material informativo e esclarecedor sobre a referida lei, e segundo o analista de redes sociais da assessoria de comunicação, o uso das redes para a divulgação da lei tem um papel muito importante para o fortalecimento da LAl. Para a equipe técnica, a divulgação da lei é uma forma de contribuir para a efetivação da mesma. Essa perspectiva foi percebida face ao monitoramento da página e a constatação do trabalho sistemático do órgão em fazer circular as notícias sobre a lei e suas possibilidades de implementação.

Observou-se que as postagens com menção direta a Lei de Acesso à Informação têm característica de divulgar e fazer conhecer melhor o funcionamento e procedimentos da lei. Sabe-se que esse tipo de divulgação proporciona um fomento e maior conhecimento sobre a lei e consequentemente maior acesso a informações públicas, a questão a ser problematizada referese as práticas que levam a transparência ativa e passiva e se essas práticas têm tronado possível o de desenvolvimento (ou não) de uma cultura de informação e politização dos temas de interesse público.

Ao longo do monitoramento percebe-se o aumento das postagens com menções diretas a LAl, observe no gráfico: 
Gráfico 2 - acompanhamento das postagens referente ao mês de maio

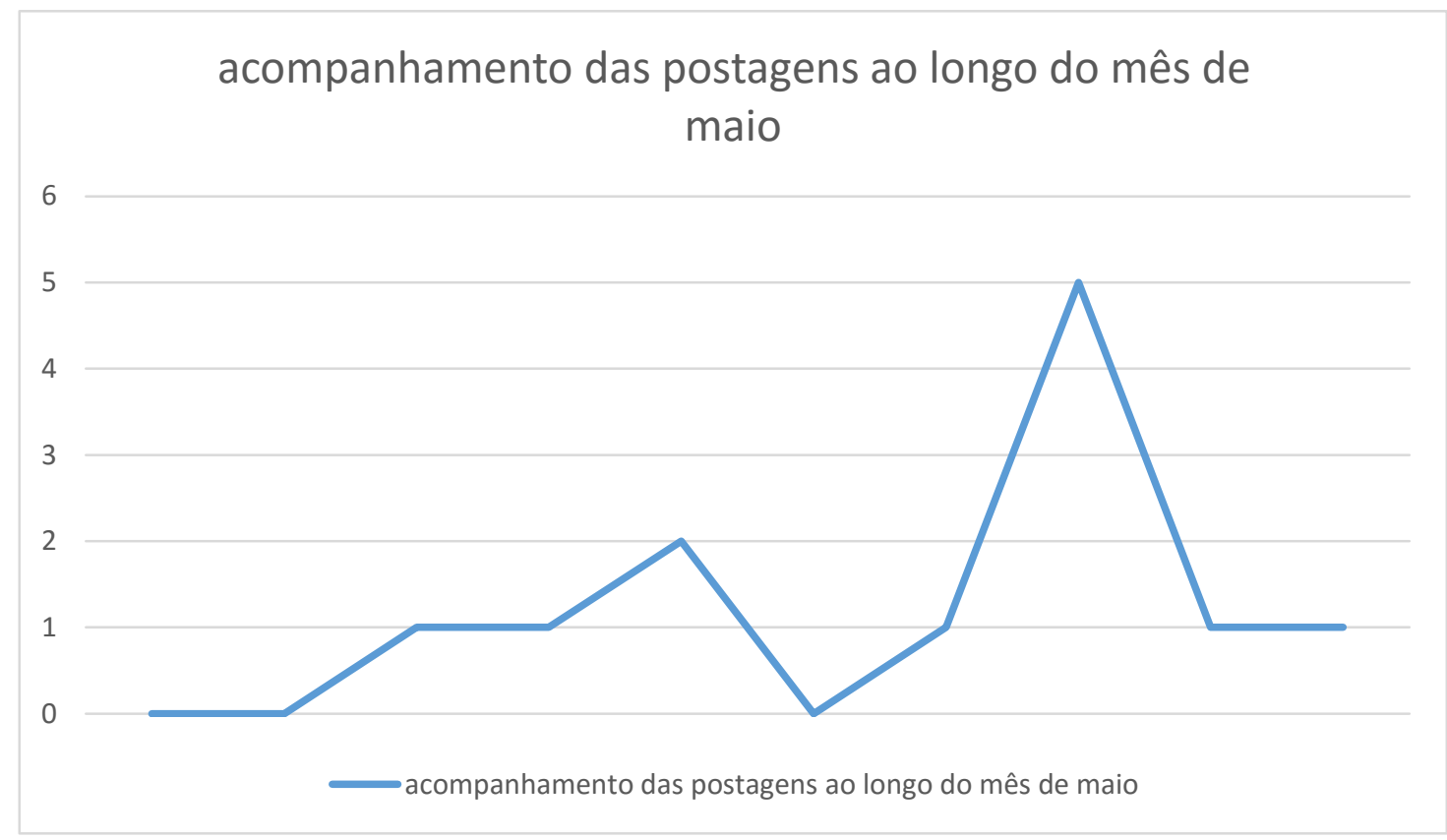

Fonte: autoria própria

O gráfico mostra o resultado da campanha de comemoração do aniversário da lei. Observa-se um pico de postagens a partir do dia 15 e no dia 16 de maio. Ocorreram muitas postagens que continham informações e dados numéricos sobre a Lei de Acesso à Informação, com a intenção de mostrar o quanto ela já vem se estruturando. Essa campanha contou com postagens comemorativas, como no exemplo, o índice de transparência que mostrava como estava a situação dos estados da Federação em relação a implementação da lei. As imagens a seguir mostram o marco criado na página oficial da CGU em comemoração ao aniversário da LAI e a postagem com o índice de transparência: 
ISSN 1981-3694

(DOI): $10.5902 / 1981369419768$

REVISTA ELETRÔNICA DO CURSD DE

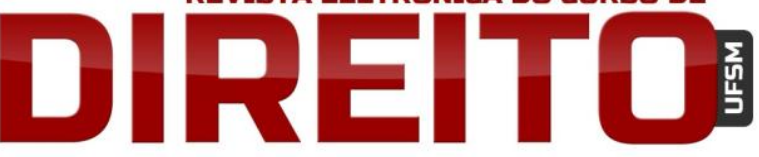

ADMINISTRAÇÃO PÚBLICA, DIREITO E REDES SOCIAIS:

O CASO DA CGU NO FACEBOOK

ANA CLÁUDIA FARRANHA LEONARDO TADEU DOS SANTOS

Imagem 5- postagem comemorativa ao aniversário da lei de acesso a informação

3 anos de vigência da Lei de Acesso à Informação! lo/

$$
16 \text { de mayo }
$$

\#3anosLAl: O Poder Executivo Federal já recebeu mais de 270 mil

solicitações de informaç̃ôes desde a vigência da Lei de Acesso à

Informação, em 16 de maio de 2012 De acordo com dados da CGU,

$98,33 \%$ das solicitações já foram respondidas, sendo que o tempo médio

de respostas foi de 13,88 dias - a lei prevê um prazo de 20 dias.

prorrogáveis por mais 10

A média mensal de solicitações tem sido de 7,3 mil pedidos e o mês que

registrou mais pedidos foi março de 2015 , com 9.878 solicitaç̃es. As

unidades da federac̃ão que mais registram pedidos pela Lei de Acesso

foram: São Paulo $(25,50 \%)$, Rio de Janeiro $(13,14 \%)$ e Minas Gerais

$(10,02 \%)$.

Saiba mais sobre os resultados da LAl nestes 3 primeiros anos em http.//OW.Iy/N5LE0

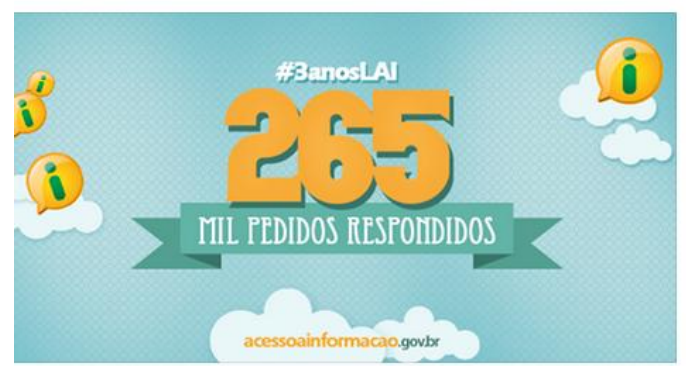

Fonte: Pagina oficial da CGU no Facebook (maio/2015)

Imagem 6 - índice de transparência elaborado pela CGU

21 de mayo -4

\#LAl: Conheça o ranking de cumprimento da Lei de Acesso nos estados e municipios 00

A Controladoria-Geral da União lançou índice que mede a transparência pública em estados e municípios brasileiros. É a Escala Brasil

Transparente (EBT), metodologia criada pela Controladoria para avaliar o grau de cumprimento às normas de Lei de Acesso (Lei 12.527/2011).

No total, foram analisados 492 municipios com até 50 mil habitantes, incluindo todas capitais, além dos 26 estados e d... Ver más

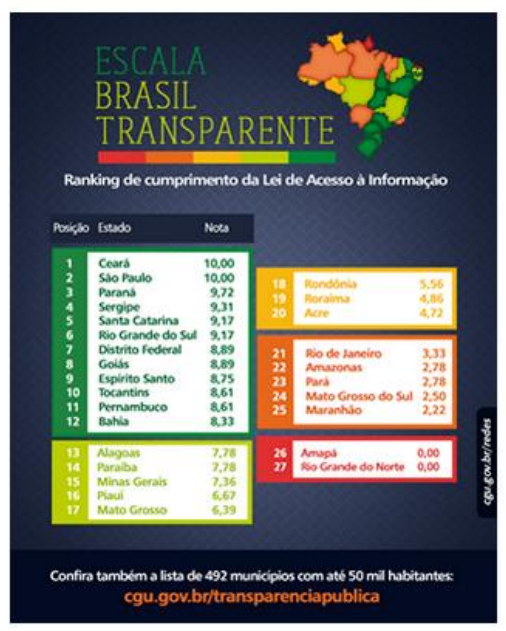

Fonte: Pagina oficial da CGU no Facebook (maio/2015) 
Infere-se que a atuação da CGU, no sentido de auxiliar a execução da lei, tem se desenvolvido e ampliado através das redes sociais. 0 mês monitorado, por ser um mês atípico, obteve maior atenção voltada para a lei; entretanto, sabe-se que em meses não atípicos as postagens sobre a lei é corriqueira.

O potencial de chamar os usuários a pesquisar mais sobre a LAl e outros programas governamentais tem se consolidado e é percebido através das interações via comentários.

\section{CONCLUSÃO}

A discussão sobre o uso das redes sociais pela Administração Pública, apesar de recente, tem apresentando uma tendência em valorar positivamente essa ocupação do espaço virtual pelos governos. Essa valorização positiva se deve ao fato de que as mídias sociais digitais têm demonstrado potencial satisfatório de participação livre e de acessibilidade. È importante ressaltar que existem obstáculos, como a exclusão digital, que impõe barreiras a maior capilaridade na relação governo e cidadão.

Reconhece-se o potencial das redes sociais na divulgação e auxílio a implementação de dispositivos de leis, como a Lei de Acesso à Informação.

Ao se discutir o fomento a uma cultura de informação e politização, infere-se que existe uma dificuldade em tornar as redes sociais em espaços de diálogo entre sociedade civil e Estado. Observa-se que muito dessa atuação segue um sentido de divulgação de informações. A prevalência de uma transparência ativa, apesar de difundir mais assuntos de teor público, pode empobrecer a interação com os internautas, pois é como se esse canal estivesse restrito ao repasse de informações e não como uma arena de diálogo com os internautas. Ou seja, existe um volume grande de informações e pouca interação de fato. O caso da CGU apresenta uma tentativa de obter maior interação, o que vem acontecendo, mas ainda de forma muito inicial e descontínua.

A presença de órgãos públicos nas redes sociais é um fator positivo ao se pensar governança, visto que o maior contato, a troca de experiências e a articulação conjunta dos atores facilitam o alcance de metas e a ampliam as relações entre o Estado e os cidadãos. 0 avanço do governo em ambientes virtuais é uma forma de dinamizar e aprimorar a governança. 
O objetivo da pesquisa foi alcançado e demonstrou a importância e o crescimento do governo eletrônico no processo fomento de informação e politização por parte dos cidadãos e como isso pode enriquecer a participação social. Também, destacaram-se os principais obstáculos enfrentados nesse campo.

Em suma, pode-se inferir que a atuação da CGU na rede social Facebook tem logrado uma interação com os internautas, porém de maneira ainda fraca. É preciso que esse canal possibilite maior diálogo e proximidade entre os atores. 0 trabalho do governo nas redes sociais também pode facilitar ações coletivas; entretanto nesse estudo não houve nenhuma caso em que confirmasse essa afirmação.

A metodologia usada, observação direta e analise de conteúdo, foi eficaz para alcançar o objetivo da investigação. Através dos dados é possível inferir que o uso das redes sociais por órgãos públicos podem auxiliar na execução de dispositivos legais normatizados e que esse uso pode fomentar, indiretamente, uma cultura de informação e politização por parte dos usuários.

O estudo apresenta limitações, tais como: amostragem por um curto espaço de tempo, apenas um mês, e sendo um mês atípico devido ao aniversário da Lei de acesso a informação.

A pesquisa serve de reflexão e estímulo para pesquisas mais aprofundadas sobre uma possível interação entre governo e sociedade civil. Destaca-se que é preciso pensar uma forma de interação mais efetiva; seja por enquetes em que visem à opinião e sugestão de usuários, seja por capacitação e aumento de funcionários em órgãos públicos voltados para a atuação em redes sociais ou pelo desenvolvimento de mecanismos que auxiliem na pesquisa entre a relação da interação dos usuários e realização de políticas públicas. Uma possível medida seria o investimento em meios que induzam a transparência passiva, aumentando a participação dos cidadãos. Para pesquisas futuras é interessante o questionamento do papel do moderador na transmissão de informações públicas e a observação do desenvolvimento de discussões de temas públicos em redes sociais digitais.

\section{REFERÊNCIAS}

BARDIN, L. Análisis de contenido. Ediciones Akal, 1991.

BRASIL. Controladoria Geral da União. Perfil oficial no Facebook. Disponível em: https://www.facebook.com/cguonline?fref=ts 
BRASIL. Controladoria Geral da União. Manual da lei de acesso a informação para estados e municípios. Brasília/2013. Disponível em:

file:///D:/Downloads/manual_lai_estadosmunicipios.pdf

CERVO, A. L. BERVIAN, P. A. Metodologia científica. 5.ed. São Paulo: Prentice Hall, 2002.

FARRANHA, A. C. et al. Administração pública e redes sociais (Facebook e Twitter): Analise de casos selecionados. Revista Negócios em Projeção; v.5, n. 1. Brasília, 2014.

FARRANHA, A. C.; OLIVEIRA, R.S, RAMINELLI, F. P. Lei de Acesso à Informação (Lei. no.

12.527/2011) e administração pública: direito à informação, proteção à intimidade e desafios para a regulação ( o caso do Ministério da Saúde). In: Tania Margarete Mezzomo Keinert, Flavia Mori Sarti, Carlos Tato Cortizo e Silvia Bastos (orgs.). Proteção à Privacidade e Acesso às Informações em Saúde: Tecnologias, Direitos e Ética. Editora do Instituto de Saúde. São Paulo, 2015

MATHIAS-PEREIRA, J. Manual de gestão pública. $1^{\circ}$ ed. São Paulo: Atlas, 2008.

MENDEL, T. Liberdade de informação: Um estudo de direito comparado. $2^{\circ}$ ed. Brasília: UNESCO,2009.

PINHO, J. A. G.de. Investigando portais de governo eletrônico de estados no Brasil: muita tecnologia, pouca democracia. Revista de Administração Pública, v. 42, n. 3, p. 471-493, 2008.

ROSENAU, J. N. Governança, Ordem e Transformação na Política Mundial. In: Rosenau, James N. e Czempiel, Ernst-Otto. Governança sem governo: ordem e transformação na política mundial. Brasília: Ed. Unb e São Paulo: Imprensa Oficial do Estado, 2000. pp. 11-46

ROVER, A. J. Introdução ao governo eletrônico: in governo eletrônico e inclusão digital. Rover, Aires José (org.). Florianópolis: Fundação Boiteux, 2009, p.95.

SAMPAIO, R. C. Participação política e os potenciais democráticos da internet. Porto Alegre: Debates, 2010.

Recebido em: 01/10/2015 / Revisões requeridas em: 18/11/2015 / Aprovado em: 30/11/2015 